\title{
Clinical and economic analysis of hospital acquired infections in patients diagnosed with brain tumor in a tertiary hospital
}

\author{
J. Undabeitia; B.G. Liu**; G. Catalán*,***; G. Bilbao*,***; I. Pomposo*,*** and J.M. Garibi*,***
}

Department of Neurosurgery. Arnau Hospital. Villanova. Lleida. Department of Neurosurgery*. Cruces Hospital. Department of Neurosurgery**. Johns Hopkins Medical Institutions. Department of Surgery***. University of the Basque Country.

Summary

Objectives. To analyze the relationship between hospital acquired infections and clinical outcomes, duration of stay, and cost per infectious episode in patients diagnosed with brain tumors in our service.

Materials and methods. We conducted a retrospective study on patients diagnosed with brain tumors and admitted to the department of neurosurgery in the Cruces Hospital of the University of the Basque Country between January 1st, 2007 and December 31st, 2007. We collected demographics, responsible pathogens, infection location, length of hospitalization, and costs of various medical and surgical procedures performed.

Results. We reviewed 139 patients that accumulated 210 hospital visits. We found 34 episodes of hospital acquired infections (16.25\% of patients). The most frequent infections were that of the lower respiratory tract, urinary tract, and surgical site. We found that patients with HAIs had a significantly lower final KPS score (sig $<0.01$, greater mean cost of stay $(17097 €$, sig.<0.01), and longer length of stay (15.45 days, sig<0.01). We did not find a significant difference in mortality.

Conclusions. We found significant association between the presence of HAIs and worse clinical outcomes, higher costs, and longer length of stay. The pathogens responsible and infection locations were similar to existing series in the literature. Although variability in study designs in the literature makes interpretation and comparison of results difficult, measures to prevent these complications can improve quality of care and reduce costs.

KEY WORDS. Brain neoplasms. Infection. Costs.

Análisis clínico económico de las infecciones nosocomiales en los pacientes diagnosticados de tumoración cerebral en un hospital terciario

Recibido: 24-04-11. Aceptado: 25-07-11.
Resumen

Objetivos. Analizar la relación entre la presencia de infección nosocomial y el resultado clínico final, la duración de la estancia y el coste del episodio en los pacientes diagnosticados de tumoración cerebral en nuestro servicio.

Material y método. Realizamos un estudio retrospectivo incluyendo los pacientes ingresados en el Servicio de Neurocirugía del Hospital Universitario de Cruces con diagnostico de tumoración cerebral en el periodo comprendido entre el 1-1-2007 y el 31-12 del 2007. Recogimos variables demográficas, los microorganismos responsables y la localización de las distintas infecciones, el tiempo de ingreso y los costes de los distintos procedimientos médicos y quirúrgicos realizados.

Resultados. Recogimos 139 pacientes, que acumularon un total de 210 episodios. Encontramos la presencia de infecciones nosocomiales en 34 episodios (16,25\%). La localización mas frecuente fue la respiratoria, seguida del tracto urinario y la infección de herida quirúrgica. Encontramos unas diferencias significativas en la situación funcional al alta ( $\mathbf{s i g}<\mathbf{0 . 0 1}$ ), el coste medio de los episodios $(17097 €$, sig. $<0.01)$ y en la estancia media (15.45 días, sig.<0.01). No encontramos diferencias significativas con respecto a la mortalidad.

Conclusiones. Encontramos asociaciones significativas entre la presencia de infección nosocomial, un peor resultado clínico, un mayor coste y una mayor estancia. Los gérmenes responsables y localizaciones fueron similares a las series previamente publicadas. A pesar de que la variabilidad en el diseño de los estudios recogidos en la literatura dificulta la interpretación y comparación de los resultados, las medidas destinadas a la prevención de esta complicación permiten simultáneamente mejorar la asistencia prestada, asi como reducir los costes generados por la enfermedad.

Abreviations. HAI: Hospital acquired infections. ICU: Intensive Care Units. KPS: Karnofsky Performance Status. LOS: length of stay. SD: standard deviations. 
PALABRAS CLAVE. Tumor cerebral. Infección. Costes.

\section{Introduction}

Hospital acquired infections (HAI) present a serious problem in patient safety, resulting in increased mortality rates, prolonged hospital stays, and higher $\operatorname{costs}^{4,9,21,22,23,28}$ $, 29,31,34,36$. HAIs rank as the fifth leading cause of death in acute care hospitals and account for approximately 88,000 deaths annually in the United States ${ }^{5,24}$. The incidence of HAI has increased 36\% from 1975 to 1995, indicating that many challenges still exist in prevention and control of $\mathrm{HAI}^{11,32,35}$.

Healthcare expenditures have experienced double digit growth over the past three decades, with incremental costs of HAI playing a significant role in the decisions of health care managers ${ }^{31}$. Consequently, economic considerations have become an increasingly important component to infection control ${ }^{8,29}$. Because the underlying goal of infection control is to protect the patient as well as others in the healthcare environment in a cost effective manner, the economic implications of HAI prevention for healthcare institutions should be investigated closely ${ }^{30}$. Economic analyses that accurately quantify tradeoffs between patient outcomes and marginal costs are crucial to helping managers make informed decisions ${ }^{14,29}$. However, differences in economic models, hospital characteristics, sample sizes, and case finding methodologies among studies have produced considerable variation in cost estimation techniques ${ }^{17,27,32}$.

Brain tumors represent $1-2 \%$ of all newly diagnosed tumors and account for $2 \%$ of all cancer-related deaths. As with other neurologic diseases, brain tumors are particularly expensive to treat, with HAIs adding to costs ${ }^{3,12}$. In this study we evaluate the epidemiology, additional length of stay, incremental costs and patient outcomes due to hospital-acquired infections in brain tumor patients. We also investigate different sites of infection and causative pathogens.

\section{Materials and methods}

The records of all the patients admitted to the Department of Neurosurgery at Cruces Hospital for brain tumors between January 1st and December 31st of 2007. Variables collected were sex, age, total length of stay, responsible microorganisms, number of days in Intensive Care Units (ICU), number of days in the ward, type of the infection (according to CDC criteria and classification), initial and final Karnofsky Performance Status (KPS) score, and cost of procedures. All data was obtained from the Medical Records and Financial Departments of our hospital.
Costs were calculated using the "microcosting" methodology, a technique in which actual costs of the items and services used by individual patients are used rather than average daily costs or cost-to-charge ratios s, $18,27,28$.

Medical records were reviewed for hospital acquired infections using the Centers for Disease Control and Prevention Criteria updated in $2008^{16,23,27,36}$. Patients were considered to have contracted a hospital-acquired infection if symptoms originated from our hospital and were not clinically manifest at the time of admission, with the exception of surgical site infections as they often do not manifest until after discharge ${ }^{6}$. Multi-site infections were considered to be separate infectious incidents ${ }^{23}$.

\section{Statistical analysis}

Data are expressed as percentages for qualitative variables and arithmetic means and standard deviations (SD) for quantitative variables. Duration of hospitalization was expressed as median and range. The Student's t test, chisquare test, and Kruskal-Wallis test were used for univariate analysis of data. Statistical significance was set at a $\mathrm{P}$ value of less than .05 . Linear regression models were used to assess the influence of variables on duration of hospitalization, total cost incurred, and final KPS. Association between variables was considered to exist when the coefficient of correlation was greater than $0.5^{21,27}$.

\section{Results}

\section{Description of sample}

The final cohort was comprised of 139 patients with 210 hospital visits and 168 surgical procedures. 53 (45.3\%) of the patients were male and $76(54.7 \%)$ were female. The mean patient age was 56.56 years and the range was 25 to 81 years. We found a total of 69 different infections in 34 $(16.2 \%)$ visits.

\section{Infection site}

The most frequent site of infection was the lower respiratory tract or pneumonia. The surgical site was the third most frequent site of infection, and the urinary tract was the second most frequent site (Table 1). Respiratory tract infections were caused most frequently by Pseudomonas aeruginosa ( $P$. aeruginosa), and urinary tract infections were caused mostly by Escherichia coli. For surgical site infections, the pathogens most frequently responsible were P. aeruginosa and Staphylococcus aureus (S. aureus). Infections of the skin and bloodstream were most often caused by $S$. aureus. Overall, $S$. aureus was the most common pathogen causing infection.

\section{Cost of Visit}

The mean total cost of all visits was $13,540.56 €$ 


\section{Table 1}

\section{Distribution of infection sites}

\begin{tabular}{lcc}
\hline Site of infection & $\mathrm{N}$ & $\%$ \\
\hline Surgical site infection & 13 & $18,8 \%$ \\
Urinary tract infection & 18 & $26,1 \%$ \\
Lower respiratory tract & & \\
Infection/pneumonia & 23 & $33,3 \%$ \\
Skin and soft tissue & & \\
Infection & 3 & $4,3 \%$ \\
Bloodstream infection & 8 & $11,6 \%$ \\
Others & 4 & $5,8 \%$ \\
TOTAL & 69 & $100,0 \%$ \\
\hline
\end{tabular}

$(\mathrm{SD}=10,493.51)$ (Table2). We found that patients with HAIs had a significantly greater cost of visit compared to patients without HAIs (sig. $<0.01$, U-Mann Whitney test). The mean cost of visit for patients with HAIs was
$27,870,00 €$ compared to $10,722.38 €$ for patients without HAIs. We developed a linear regression model relating total cost to the number of HAIs and patient age: (Total Cost $)=15178.93+(8197.06 \times$ number of HAIs $)-(76.58$ $\mathrm{x}$ age). The coefficient of correlation was 0.73 . (Figure 1)

\section{Length of Stay (LOS)}

The mean LOS for all patients was 14.34 days (Table 2). We found that patients with HAIs had a significantly greater LOS compared to patients without HAIs (sig. $<0.01$, U-Mann Whitney test). The mean LOS for patients with HAIs was 35.65 days compared to 10.23 days for patients without HAIs. We developed a linear regression model relating LOS to the number of HAIs: $($ LOS, days $)=11.407$ $+(11.566 \mathrm{x}$ number of HAIs) (Figure 2).

The coefficient of correlation was 0.74 (Figure 3).

\section{Clinical Outcome}

We found that patients with HAIs had a significantly lower KPS upon discharge compared to patients without

Table 2

Total costs, total length of stay, ICU length of stay, floor length of stay (Mean \pm SD) of patients with and without HAI

\begin{tabular}{lccccr}
\hline & N (\%) & $\begin{array}{c}\text { Total LOS } \\
\text { (days) }\end{array}$ & $\begin{array}{c}\text { Floor LOS } \\
\text { (days) }\end{array}$ & $\begin{array}{c}\text { ICU LOS } \\
\text { (days) }\end{array}$ & \multicolumn{1}{c}{ Total Costs (€) } \\
\hline No HAI visits & $176(83,75 \%)$ & $10,2 \pm 8,1$ & $8,5 \pm 7,1$ & $1,7 \pm 2,4$ & $10.772,4 \pm 6397,9$ \\
HAI visits & $34(16,25 \%)$ & $35,65 \pm 23,1$ & $22,06 \pm 20,5$ & $13,59 \pm 11,1$ & $27.870,00 \pm 15096,1$ \\
Total & $210(100 \%)$ & $14,34 \pm 15,078$ & $10,69 \pm 11,564$ & $3,6 \pm 6,615$ & $13.540,56 \pm 10493,51$ \\
\hline
\end{tabular}
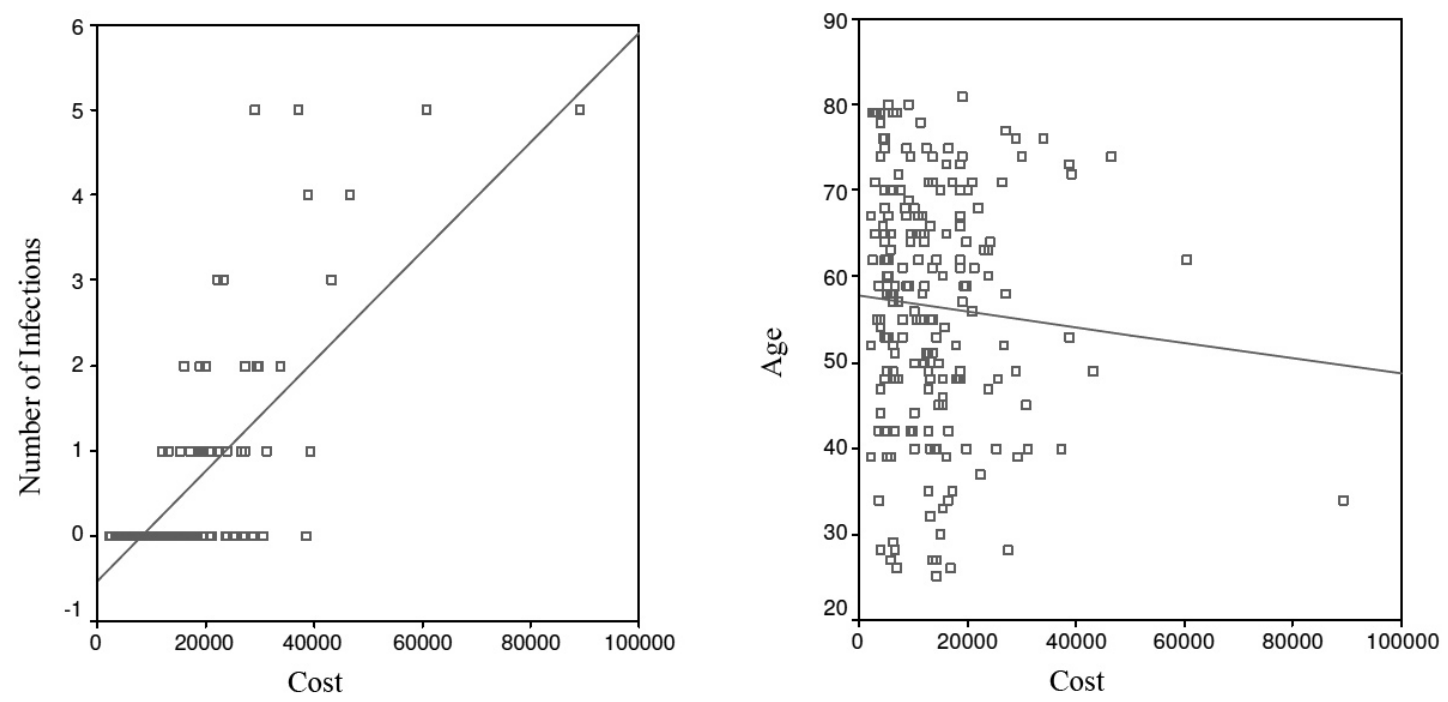

Figure 1. Linear correlation between costs and number of HAI and age. 


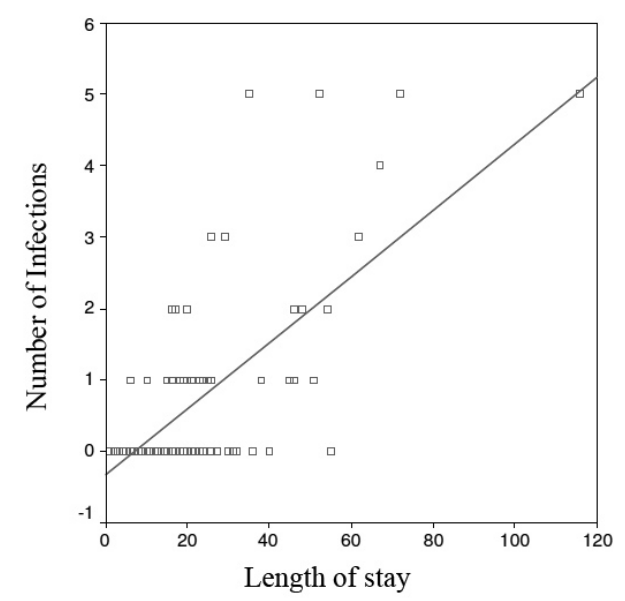

Figure 2. Linear correlation between number of HAI and LOS.
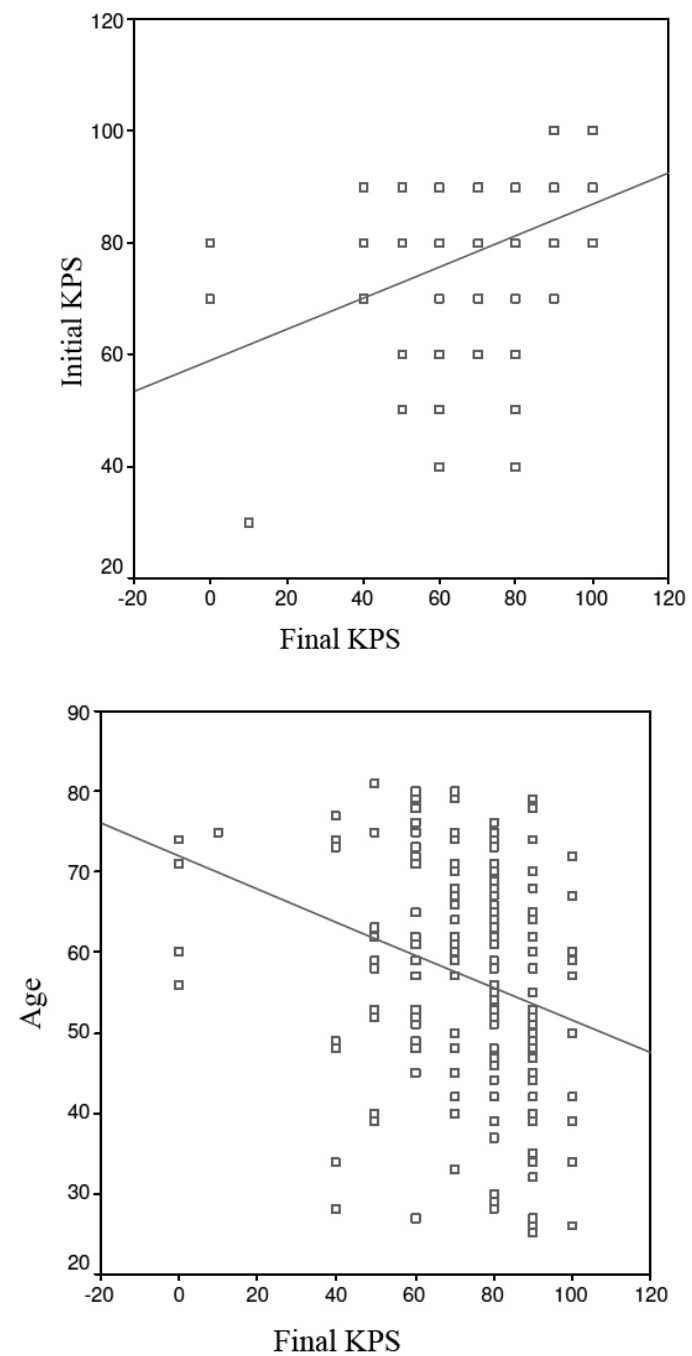

HAIs (chi squared, sig <0.01). For example, 91.9\% of patients without HAIs had a final KPS in the range of 80100 , but only $8.1 \%$ of patients with HAIs had KPS score in this range. We developed a linear regression model for relating final KPS to initial KPS, number of HAIs, and age: $($ Final KPS $)=46.428+(0.564 \times$ Initial KPS $)-(7.356 x$ number of HAIs) - (0.277 $\mathrm{x}$ age). The coefficient of correlation was 0.609 .

We did not find a significant difference in mortality between patients with or without HAIs ( $p=0.64$, chi-squared test). There were four cases of deceased patients, and two of these patients had HAIs as a complication. However, the difference was not significant due to small sample size.

\section{Discussion}

The hospital environment is by nature conducive to HAI due to a high level of patient-caregiver interaction,

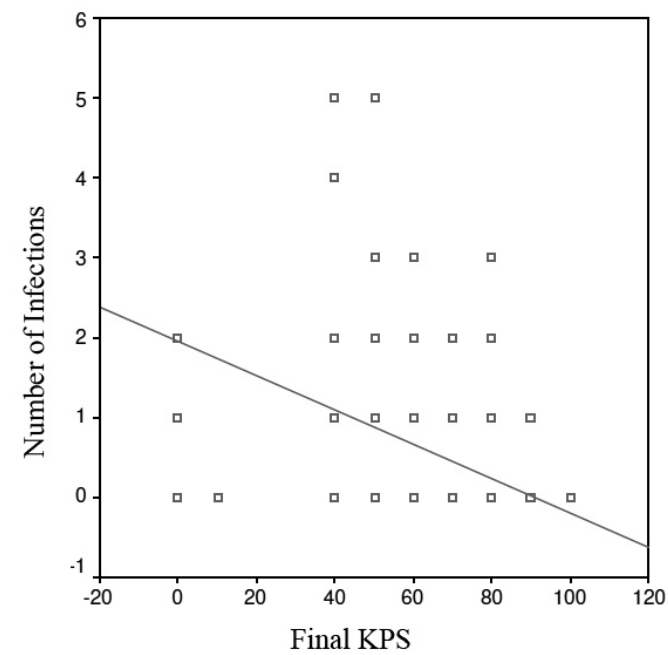


a patient population with increased susceptibility to infection, and breach of safety guidelines such as proper hand hygiene and application of perioperative antibiotics ${ }^{33,35}$. Most cases involve routinely used invasive devices such as ventilators or venous and urinary catheters. Multiple drugresistant organisms (MDROs) play an especially significant role, with more than $70 \%$ of bacteria known to cause HAIs having resistance to at least one drug due to increased usage of broad-spectrum antibacterial agents for previous infections $^{31}$. There is also evidence showing that MDRO related infections are associated with longer LOS, greater consumption of resources, and poorer outcomes ${ }^{20,22,24,33}$.

\section{Responsible pathogens}

Our study agrees with literature in that the lower respiratory tract was the most frequent site of nosocomial infection. However, we found that the urinary tract was the second most common site of HAI, while other studies find that surgical wound infection is the second most common site in surgery patients. In accordance with literature, we found that $S$. aureus and $P$. aeruginosa were the most common pathogen responsible for HAIs ${ }^{20,22,23}$. Although this was not the primary aim of our study, one future question to be investigated would be the modes of transmission and factors associated with strain-specific HAIs.

\section{Patient outcomes}

All the articles we reviewed showed poorer outcomes for patients with HAI. In our study, we found that patients with HAIs have a significantly lower KPS score than patients without HAIs. According to our linear regression model, each additional episode of HAI decreases KPS by 7.356. For this analysis, we treat KPS as a continuous variable in order to perform the linear regression. To the best of our knowledge this is the first study that studies the effect of HAIs on outcomes in terms of KPS. There is a growing consensus that HAI is directly related to increased mortality ${ }^{4,22,36}$. However, there were only four deaths in our sample and we did not show statistical significance for mortality $(\mathrm{p}=0.64)$.

\section{Impact on length of stay}

The average LOS for patients with HAIs was 25.42 more days than patients without HAIs (sig <0.01). Using our linear regression model, we found that each episode of HAI increases the LOS by an additional 11.566 days. This agrees roughly with literature values for mean difference in LOS between surgery patients with and without HAIs. HAIs disrupt the normal course of recovery and prevent patients from returning home earlier. Consequently, extended hospital stays prevent access to hospital beds for other patients, especially for institutions with a high volume of patients ${ }^{19}$. Such complications present a formidable oppor- tunity cost to hospitals due to insufficient room to accommodate new patients ${ }^{11}$.

Overcrowded health institutions would stand to benefit from more effective infection control due to increased availability of hospital beds ${ }^{27}$.

\section{Impact on Costs}

Furthermore, the average cost of stay for patients with HAIs was 17,097.62€ greater compared to patients without HAIs. The large standard deviation for total costs reflects the wide range of total cost estimates found in the literature for HAIs in surgery patients. Variations in the literature also include differences among patient populations $s^{14,17,27,32,33}$. The linear regression model showed that each infection added an additional $8,197 €$ to the total cost of stay. An unexpected finding was that patients greater in age were associated with lower costs. This is most likely due to the fact that older patients are less likely to undergo aggressive surgical procedures, resulting in fewer complications and shorter recovery time $\mathrm{e}^{2,7,15}$.

\section{Economic implications}

The considerable increase in LOS and costs for patients contracting HAIs indicates the economic implications that careful monitoring of such complications could have for health care institutions. Effective infection control measures may significantly reduce financial burden for hospitals, allowing for resources to be allocated toward other needs ${ }^{9,10}$. For example, each additional day of stay due to HAIs is costly to hospitals and limits the number of patients that can receive treatment at a given time. Infection control programs that successfully reduce HAIs result in cost savings, but the cost of these programs must be compared to the cost savings due to HAI control ${ }^{13,26}$. Even with conservative estimates for benefits of HAI prevention, it is likely that the cost of infection control programs will be lower than cost savings due to HAI control for many institutions ${ }^{11,14}$. Additionally, the mean additional cost of HAIs themselves often exceed the cost of the actual surgery ${ }^{8}$. From our study we suggest that the benefits of HAI prevention are twofold in that it is valuable for improving both quality of patient care and reducing unreimbursed costs ${ }^{1,25,27}$.

\section{Limitations}

Microcosting, or the use of direct costs of hospitalization such as specific items and services used by a given patient, has been suggested as a more accurate means for estimations of HAI associated costs. However, the method does not fully account for larger scale effects such as loss of productivity and income, and we did not attempt to estimate such impacts on personal life. Further, because the time horizon of this study was relatively short, it cannot be used for analyses regarding economic burden in long-term 
care facilities and outpatient centers ${ }^{18,22,29,31,34}$.

Additionally, studying the relationship between LOS and infection rates often ends in the classic "chicken or the egg" dilemma. That is, the LOS of a patient with an HAI could increase due to time required for treatment, but patients with a longer LOS have a greater probability of contracting an HAI. As a result, we must ask whether HAIs cause higher costs and a longer LOS, or HAIs are an inevitable result of long hospitalizations $\mathrm{s}^{11,13,17}$. For retrospective studies such as ours, association but not causation can be extrapolated. Because infection control studies are subject to a variety of confounding factors including comorbidities and severity of disease, isolating the effect of HAIs on LOS and cost of visit can be difficult ${ }^{8}$.

\section{Conclusion}

Although advancing the standard of care has been traditionally focused on patient safety, health care savings have recently been associated with improved outcomes, prompting an emphasis on economic evaluation among healthcare institutions. As a result, multi-disciplinary collaboration between infection control authorities and experts from other fields is becoming increasingly crucial to properly informing decision makers. Because brain tumor patients often receive complex and expensive treatments, optimal allocation of resources is crucial to both hospital operation and patient outcomes. We conclude from our study that in the current economic climate, infection control is an important component not only for patient safety, but also for the effective use of resources.

\section{References}

1. Anderson, D.J., et al.: Underresourced hospital infection control and prevention programs: penny wise, pound foolish? Infect Control Hosp Epidemiol 2007; 28: 767-773.

2. Barnholtz-Sloan, J.S., et al.: Patterns of care and outcomes among elderly individuals with primary malignant astrocytoma. J Neurosurg 2008; 108: 642-648.

3. Blomqvist, P., et al.: Brain tumours in Sweden 1996: care and costs. J Neurol Neurosurg Psychiatry 2000; 69: 792798.

4. Burgmann, H., et al.: Impact of nosocomial infections on clinical outcome and resource consumption in critically ill patients. Intensive Care Med 2010; 36: 1597-1601.

5. Burke, J.P.: Infection control - a problem for patient safety. N Engl J Med 2003; 348: 651-656.

6. Byrne, D.J., et al.: Wound infection rates: the importance of definition and post-discharge wound surveillance. $\mathrm{J}$ Hosp Infect 1994; 26: 37-43.

7. Chaichana, K.L., et al.: Supratentorial glioblastoma multiforme: the role of surgical resection versus biopsy among older patients. Ann Surg Oncol 2011; 18: 239-245.

8. Chen, Y.Y., Chou, Y.C., Chou, P.: Impact of nosocomial infection on cost of illness and length of stay in intensive care units. Infect Control Hosp Epidemiol 2005; 26: 281-287.

9. Cohen, D.R.: Economic issues in infection control. J Hosp Infect 1984; 5 Suppl A: 17-25.

10. Drummond, M.F., Davies L.M.; Evaluation of the costs and benefits of reducing hospital infection. J Hosp Infect 1991; 18 Suppl A: 85-93.

11. Dulworth, S., Pyenson, B.; Healthcare-associated infections and length of hospital stay in the Medicare population. Am J Med Qual 2004; 19: 121-127.

12. Ekman, M., Westphal, M.: Cost of brain tumour in Europe. Eur J Neurol 2005; 12 Suppl 1: 45-49.

13. Graves, N., et al.: Estimating the cost of health careassociated infections: mind your p's and q's. Clin Infect Dis 2010; 50: 1017-1021.

14. Graves, N.; Economics and preventing hospital-acquired infection. Emerg Infect Dis 2004; 10: 561-566.

15. Grossman, R., et al.: Predictors of inpatient death and complications among postoperative elderly patients with metastatic brain tumors. Ann Surg Oncol 2011; 18: 521-528.

16. Horan, T.C., Andrus, M., Dudeck, M.A.: CDC/NHSN surveillance definition of health care-associated infection and criteria for specific types of infections in the acute care setting. Am J Infect Control 2008; 36: 309-332.

17. Kilgore, M.L., et al.: The costs of nosocomial infections. Med Care 2008; 46:101-104.

18. Kirkland, K.B., et al.: The impact of surgical-site infections in the 1990s: attributable mortality, excess length of hospitalization, and extra costs. Infect Control Hosp Epidemiol 1999; 20: 725-730.

19. Lagoe, R.J., Westert, G.P.: Evaluation of hospital inpatient complications: a planning approach. BMC Health Serv Res 2010; 10: 200.

20. National Nosocomial Infections Surveillance (NNIS) System Report, data summary from January 1992 through June 2004, issued October 2004. Am J Infect Control 2004; 32: $470-485$.

21. Olaechea, P.M., et al.: Epidemiology and impact of nosocomial infections. Med Intensiva 2010; 34: 256-267.

22. Olaechea, P.M., et al.: Factors related to hospital stay among patients with nosocomial infection acquired in the intensive care unit. Infect Control Hosp Epidemiol 2003; 24: 207-213.

23. Orsi, G.B., et al.: Hospital-acquired infection surveillance in a neurosurgical intensive care unit. J Hosp Infect 2006; 64: 23-29.

24. Peng, M.M., Kurtz, S., Johannes, R.S.: Adverse outcomes from hospital-acquired infection in Pennsylvania cannot be attributed to increased risk on admission. Am J Med Qual 2006; 21: 17S-28S.

25. Perencevich, E.N., et al.: Raising standards while 
watching the bottom line: making a business case for infection control. Infect Control Hosp Epidemiol 2007; 28: 1121-1133.

26. Plowman, R., et al.: The rate and cost of hospitalacquired infections occurring in patients admitted to selected specialties of a district general hospital in England and the national burden imposed. J Hosp Infect 2001; 47: 198209.

27. Roberts, R.R., et al.: Costs attributable to healthcareacquired infection in hospitalized adults and a comparison of economic methods. Med Care 2010; 48: 1026-1035.

28. Safdar, N., et al.: Clinical and economic consequences of ventilator-associated pneumonia: a systematic review. Crit Care Med 2005; 33: 2184-2193.

29. Saint, S., Chenoweth, C., Fendrick, A.M.: The role of economic evaluation in infection control. Am J Infect Control 2001; 29: 338-344.

30. Scheckler, W.E., et al.: Requirements for infrastructure and essential activities of infection control and epidemiology in hospitals: a consensus panel report. Society for Healthcare Epidemiology of America. Infect Control Hosp Epidemiol 1998; 19: 114-124.

31. Sheng, W.H., et al.: Comparative impact of hospitalacquired infections on medical costs, length of hospital stay and outcome between community hospitals and medical centres. J Hosp Infect 2005; 59: 205-214.

32. Stone, P.W., Braccia, D., Larson, E.: Systematic review of economic analyses of health care-associated infections. Am J Infect Control 2005; 33: 501-509.

33. Stone, P.W., Kunches, L., Hirschhorn, L.: Cost of hospital-associated infections in Massachusetts. Am J Infect Control 2009; 37: 210-214.

34. Stone, P.W.: Economic burden of healthcare-associated infections: an American perspective. Expert Rev Pharmacoecon Outcomes Res 2009; 9: 417-422.

35. Weinstein, R.A.: Nosocomial infection update. Emerg Infect Dis 1998; 4: 416-420.

36. Ylipalosaari, P., et al.: Intensive care acquired infection is an independent risk factor for hospital mortality: a prospective cohort study. Crit Care 2006; 10: R66.

Undabeitia, J.; Liu, B.G.; Catalán, G.; Bilbao, G.; Pomposo, I.; Garibi, J.M.: Clinical and economic analysis of hospital acquired infections in patients diagnosed with brain tumor in a tertiary hospital. Neurocirugía 2011; 22: 535-541.

Correspondencia: J. Undabeitia. Email: joseundabeitia@hotmail.com 